\title{
VARIAÇÃO DA ENERGIA E SUA REPERCUSSÃO NAS CARACTERÍSTICAS COMPOSICIONAIS E TEXTURAIS EM SEDIMENTOS PRAIAIS ATUAIS: EXEMPLO DA COSTA LESTE DA BAÍA DE TODOS OS SANTOS, BAHIA, BRASIL
}

\author{
GERALDO S. VILAS BOAS* \& ABÍLIO C.S.P. BITTENCOURT*
}

\begin{abstract}
ENERGY VARIATION AND ITS REPERCUSSION ON THE COMPOSITIONAL AND TEXTURAL CHARACTERISTICS IN RECENT BEACH SEDIMENTS: EXAMPLE OF THE EAST COAST OF TODOS OS SANTOS BAY, BAHIA, BRAZIL. The beach belt on the east coast of Todos os Santos Bay shows a great variability in mechanical energy which has a strong repercussion on the compositional and textural characteristics of its sediments. In terms of composition, the energy level controls the relative amount of skeletal carbonate fragments in its sediments. Texturally, the main effect of the energy variation is to change the pattern of the cumulative grain-size curves. Based on these patterns the following zones of distinct energy levels have been identified: 1. high-energy zones, where water turbulence is strong enough to transport in suspension grain of diameter up to $0.25 \mathrm{~mm} ; 2$. moderate-energy zones, where the turbulence is just enough to prevent the deposition of grains smaller than $0.031 \mathrm{~mm}$ - the size range between $0.031 \mathrm{~mm}$ and $2 \mathrm{~mm}$ are transported by saltation; 3. low-energy zone with a weak turbulence such that the sedimentation of mud particles can also take place. Representative sedimentary parameters, such as median, standard deviation and skewness are strongly influenced by energy variations within more restrict sectors where the textural characteristics of the source rock are relatively homogeneous.
\end{abstract}

Keywords: Beach sediments, textural parameters, recent sediments.

RESUMO A faixa praial da costa leste da Baía de Todos os Santos é caracterizada por uma grande variabilidade de condições de energia mecânica, que tem ampla repercussão sobre as características composicionais e texturais dos sedimentos. Sobre sua composição, a variação da energia afeta, sobretudo, a quantidade relativa de componentes esqueletais carbonáticos presentes nos mesmos. Sobre a textura, o principal efeito dessa variação é o de causar mudanças nos padrões das curvas granulométricas. Com base nesses padrões, foram distinguidas, na área estudada, zonas com níveis distintos de energia, a saber: 1. zonas de alta energia, nas quais a turbulência da água é forte o bastante para promover o transporte por suspensão de partículas com diâmetro de até $0,25 \mathrm{~mm} ; \mathbf{2}$. zonas de energia moderada, em que a intensidade da turbulência é suficiente apenas para não permitir a deposição de partículas menores do que $0,031 \mathrm{~mm}$ - os grãos na faixa granulométrica entre 0,031 e $2 \mathrm{~mm}$ são transportados por saltação; 3. zona de baixa energia, cuja fraca turbulência possibilita a sedimentação de partículas lamosas. Os parâmetros sedimentares estatísticos, tais como a mediana, o desvio padrão e a assimetria, mostraram-se fortemente influenciados por variações da energia dentro de setores mais restritos, onde as características texturais da rocha fonte são relativamente homogêneas.

Palavras-chaves: Sedimentos praiais, parâmetros texturais, sedimentos recentes.

INTRODUÇÃO Os estudos sobre as características texturais de sedimentos praiais atuais têm sido conduzidos, na sua grande maioria, para a compreensão dos processos de transporte e deposição, e para a obtenção de dados que permitam distingui-los de outros depositados em ambientes diversos, tais como, o eólico e o fluvial. Poucos trabalhos, (por exemplo, Nordstrom 1975 e 1977) têm sido feitos visando a utilização das características texturais para diferenciar sedimentos praiais depositados em diferentes condições de exposição à ação das ondas ou em níveis distintos de energia.

O presente trabalho se propõe, fundamentalmente, a investigar a influência da variação da energia ambiental nas características composicionais e texturais dos sedimentos praiais da costa leste da Baía de Todos os Santos (Fig. 1). A escolha da área foi feita, sobretudo, pela grande variabilidade de condições de energia e de exposição à ação das ondas, existentes ao longo da mesma. Muito pouco se conhece sobre as características texturais e composicionais dos sedimentos praiais da área, e sobre os processos sedimentares envolvidos na deposição dos mesmos. Os escassos dados existentes são os do trabalho de Sestini (1967), que efetuou um estudo comparativo das características texturais dos sedimentos praiais da orla oceânica da cidade de Salvador (Fig. 1) e do interior da Baía de Todos os Santos. Nesse estudo, apenas nove amostras da região do estirâncio foram coletadas ao longo de toda a costa leste da baía, sendo que seis delas, concentradas na porção mais ao norte. Portanto, os dados e as conclusões obtidas restringem-se, basicamente, a um trecho localizado da costa leste da baía, carecendo a maior parte dessa área de um estudo mais detalhado. Uma caracterização mais ampla dos sedimentos praiais, e um melhor conhecimento dos processos sedimentares atuantes na deposição dos mesmos poderão trazer importantes subsídios para o gerenciamento da região costeira da área.

\section{ASPECTOS FISIOGRÁFICOS E GEOLÓGICOS $\mathrm{Na}$} área estudada (Fig. 1), o litoral tem uma configuração muito recortada, começando ao sul com a península de Itapagipe, que fecha parcialmente uma pequena baía do mesmo nome e estendendo-se até a Ponta do Toque-Toque. A faixa litorânea foi dividida em três setores (I, II e III), de acordo com as diferentes características fisiográflcas da costa, a saber: 1 . Setor I - compreende o trecho situado mais ao sul da área, onde a configuração da costa é ligeiramente côncava. A faixa continental adjacente é constituída por um antigo pontal arenoso, formado entre 3.000 e 3.600 anos AP (Vilas Boas \& Nascimento 1979), no qual afloram sedimentos arenosos inconsolidados, de composição essencialmente quartzosa. A faixa praial é contínua ao longo de todo o setor, com o estirâncio apresentando largura de 25 a $50 \mathrm{~m}$ na maré baixa e declive inferior a $3^{\circ}$ Na parte sul do setor I, a linha da costa projeta-se formando um 


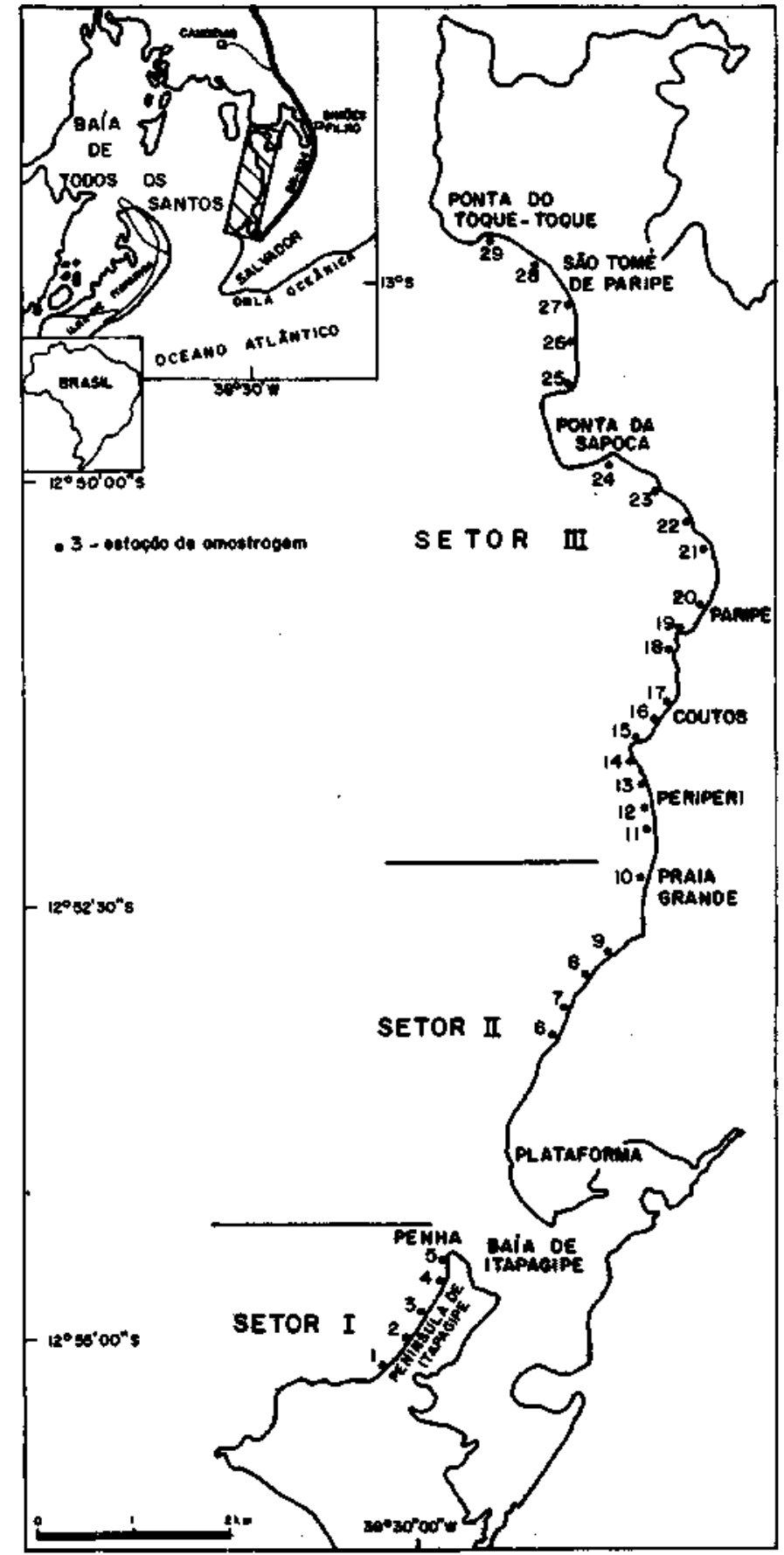

Figura l - Mapa de localização da área mostrando as estações de amostragem

Figure 1 - Location map of the studied area showing the sampling stations

promontório rochoso que toma a metade sul desse setor mais protegida da ação das ondas; 2 . Setor $\mathrm{n}$ - engloba o trecho situado na parte central da área, entre as localidades de Plataforma e Praia Grande, onde a costa tem uma configuração convexa. Ocorrem, nesse trecho, rochas sedimentares do Cretáceo Inferior (Viana et al 1971, Inda \& Barbosa 1978), constituídas por arenitos e lamitos. Os arenitos são de composição essencialmente quartzosa, e nos lamitos, estão presentes minerais dos grupos da caolinita, illita e esmectita (Conceição 1973, SME1975), e quartzo. Na metade sul desse setor, não há desenvolvimento de praias arenosas, com a faixa continental terminando em escarpas e falésias abruptas que sofrem o ataque direto das ondas, durante a preamar. $\mathrm{Na}$ metade norte, as praias constituem faixas arenosas descontínuas, com estirâncios de pouca largura (de 15 a $25 \mathrm{~m}$ na maré baixa) e declives inferiores a 3 ; 3 . Setor III - abrange a parte mais ao norte da área, entre a localidade de Praia Grande e a ponta do Toque-Toque, onde aparecem enseadas contendo praias arenosas, separadas por pontas rochosas. As povoações de Periperi, Coutos e Paripe, situadas nas bordas dessas enseadas, foram construídas sobre patamares de areias quartzosas inconsolidadas, cujos topos situam-se de alguns centímetros a até $4 \mathrm{~m}$ acima do nível atual do mar, constituindo terraços marinhos holocênicos (Bittencourt et al. 1979, Martin et al 1980). No restante da faixa continental, afloram os arenitos e lamitos cretácicos que também ocorrem no setor II. Nas faixas praiais do Setor m, as larguras dos estirâncios podem chegar até mais de $100 \mathrm{~m}$ na maré baixa, sendo seus declives inferiores a $3^{\circ}$.

As frentes de onda que chegam à Baía de Todos os Santos são geradas, em grande parte, em sua região oceânica adjacente, sendo induzidas, quase sempre pelos ventos predominantes provenientes de leste e de sudeste. Ao entrarem na baía, elas sofrem refração, abrindo-se em um amplo leque. Na parte sul do trecho estudado, elas alcançam a costa guardando ainda grande parte da energia, propiciando a formação de correntes de deriva, que rumam para norte. À medida em que se deslocam para o interior da baía, as ondas vão perdendo gradativamente a energia, diminuindo também, cada vez mais, o ângulo com que incidem sobre a costa.

A superfície do fundo da antepraia nos setores I e II forma uma extensa plataforma de declividade bastante suave.As profundidades em uma faixa adentrando até cerca de $100 \mathrm{~m}$ na antepraia são, em geral, inferiores aim. Isso induz a quebrada maioria das ondas e a dissipação de parte da energia ainda distante da costa. Desse modo, nesses setores, a turbulência da água e, conseqüentemente, a ação de joeiramento, são mais intensas na antepraia do que no estirâncio. No setor III, as pequenas ondas que chegam às enseadas quebram, quase sempre, no estirâncio. A agitação da água no estirâncio é mais intensa do que na antepraia adjacente, onde a turbulência é bastante reduzida.

AMOSTRAGEM E PROCESSAMENTO DAS AMOSTRAS A coleta de amostras foi efetuada em 29 estações de amostragem distribuídas ao longo da área (Fig. 1) e, sempre que possível, em pares antepraia-estirâncio. Em todos os casos, as amostras foram colhidas nas primeiras lâminas da superfície, até $3 \mathrm{~cm}$ de profundidade. As amostras da antepraia, em número de 29 , foram tomadas com lâminas de água em tomo de 0,5 a $1 \mathrm{~m}$; as do estirâncio, num total de 27 , na zona de espraiamento.

Após secagem, cada amostra foi quarteada e reduzida para uma quantidade de cerca de 150 g. Procedeu-se, em seguida, à eliminação dos sais solúveis, da matéria orgânica $\left(\mathrm{H}_{2} \mathrm{O}_{2}\right.$ a 110 vol.) e do material carbonático ( $\mathrm{HC1}$ a $10 \%)$. Após esse tratamento, uma porção de cerca de $50 \mathrm{~g}$ foi separada para ser peneirada a úmido na peneira de $0,031 \mathrm{~mm}$. A fração superior a $0,031 \mathrm{~mm}$ foi peneirada a seco com Rotap, através de um conjunto de peneiras espaçadas de $1 \varnothing$. O material com granulometria inferior a $0,031 \mathrm{~mm}$ foi submetido a análise granulométrica, por meio da pipetagem. Com base nos dados da análise granulométrica, foram construídas curvas granulométricas cumulativas, utilizando-se papel logprobabilístico. Para cada curva, foi feita a determinação da mediana, do desvio padrão e da assimetria. A primeira foi obtida diretamente da curva, e os dois últimos parâmetros foram calculados pelas fórmulas propostas por Folk \& Ward (1957).

O estudo da composição dos sedimentos foi efetuado utilizando-se lupa binocular e por difração de raios X. Para cada amostra, foi determinada a porcentagem de $\mathrm{CaCO}_{3}$, por diferença de peso, após a eliminação dos componentes carbonáticos com $\mathrm{HCl}$. 
COMPOSIÇÃO E ORIGEM DOS SEDIMENTOS Na área estudada ocorrem, predominantemente, sedimentos arenosos compostos de quartzo e fragmentos carbonáticos. Esses sedimentos contêm, quase sempre, uma quantidade variável de grãos carbonáticos com granulometria superior a $2 \mathrm{~mm}$, constituindo-se, de fato, em areias cascalhosas ou, muito raramente, cascalhes arenosos. Na parte sul do setor II, muito embora não haja o desenvolvimento de praias arenosas, é possível observar, na maré baixa, a ocorrência de grande quantidade de blocos e seixos de arenito, folhelho e siltito, depositados no sopé das falésias e escarpas esculpidas nas rochas cretácicas ali aflorantes.

O quartzo presente nos sedimentos deriva essencialmente da erosão das rochas sedimentares cretácicas e dos depósitos holocênicos que ocorrem no trecho estudado. A fração carbonática é constituída de esqueletos e fragmentos esqueletais de organismos marinhos principalmente moluscos, algas Halimeda, equinodermas e gasterópodos. Esses organismos vivem na antepraia e regiões mais profundas do fundo da Baía de Todos os Santos, sendo a presença de fragmentos de seus esqueletos, nos sedimentos do estirâncio, um testemunho do efetivo transporte no sentido da baía para o continente. A porcentagem de $\mathrm{CaCO}_{3}$ representada em cada estação de amostragem pela média das porcentagens presentes nas amostras do estirâncio e da antepraia cresce exponencialmente com a distância do ponto de amostragem em relação à entrada da baía, existindo um índice de correlação de $71,5 \%$ entre as mesmas (Fig. 2). Esse comportamento está associado com a diminuição da energia da região de entrada para o interior da baía, o que favorece um maior desenvolvimento dos organismos, resultando no aumento conseqüente da quantidade de partículas carbonáticas. Comportamento análogo foi observado por Vilas Boas \& Bittencourt (1979) para a fração com granulometria inferior a $0,002 \mathrm{~mm}$, dos sedimentos do fundo da Baía de Todos os Santos, onde existe um aumento gradativo do teor de $\mathrm{CaCO}_{3}$, da região de entrada para o interior como reflexo do incremento crescente da quantidade de organismos, à proporção que a energia diminui. Relações semelhantes foram também verificadas por Bittencourt (1975) para os sedimentos praiais atuais da orla oceânica de Salvador, onde as maiores quantidades de partículas carbonáticas ocorrem nos trechos cuja energia das ondas é menos intensa. A fração lamosa encontrada na maioria das amostras da antepraia do setor III é composta essencialmente de minerais

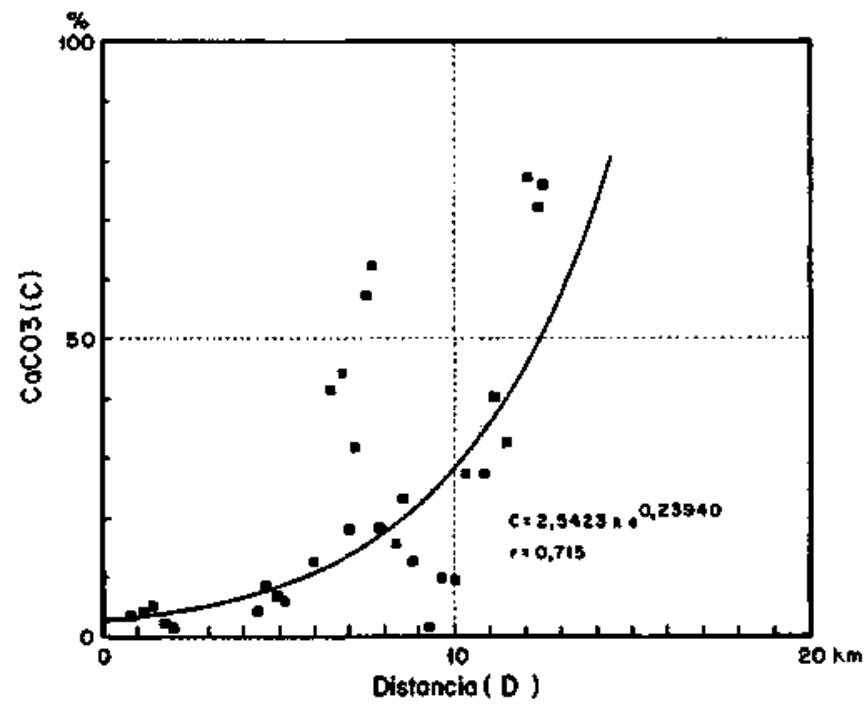

Figura 2 - Relação entre a porcentagem de $\mathrm{CaCO}_{3}$ e a distância da amostra para a região de entrada da baía

Figure 2 - Plot of the relative amount of $\mathrm{CaCO}_{3}$ against sample distance from the bay entrance dos grupos da caolinita, illita e esmectita, e de calcita, aragonita e quartzo. De forma similar ao que acontece com a fração lamosa dos sedimentos do fundo da Baía de Todos os Santos (Vilas Boas \& Bittencourt 1979), a maior parte do quartzo e dos argUominerais derivam da erosão das rochas cretácicas aflorantes na área. Uma menor proporção desses minerais pode ter como fonte as rochas de um complexo granulítico arqueano que afloram a leste da região estudada. A calcita e a aragonita constituem um material detrítico, resultante da desagregação dos componentes esqueletais carbonáticos.

\section{CARACTERÍSTICAS} DOS SEDIMENTOS Curvas granulométricas A observação das curvas granulométricas dos sedimentos (Fig. 3) mostra que o transporte por saltação é amplamente dominante ao longo da área estudada, à exceção da região da antepraia do setor III, onde o transporte por suspensão é equivalente ou mesmo, em muitos casos, mais importante que aquele.

O padrão das curvas das amostras do estirâncio (Figs. 3D, E e F) mostra variações que estão intimamente ligadas com a diminuição da energia, à medida que se passa do setor I para os setores II e III. As variações mais significativas incluem: $\mathbf{1 .}$ aumento, na população por saltação, da porcentagem do material com granulometria entre 0,125 e $0,062 \mathrm{~mm}$. Essa porcentagem passa de menos de $5 \%$ no setor I, para valores de até $15 \%$ no setor II e de até $30 \%$ no setor III. Isso resulta em uma diminuição da inclinação dos segmentos das curvas que correspondem à população por saltação e, conseqüentemente, no empobrecimento do selecionamento da mesma. É interessante observar que uma variação semelhante se verifica ao longo do estirâncio do setor I (Fig. 3D), como conseqüência da diminuição da energia, quando se passa de sua parte norte mais exposta à ação das vagas, para a região sul, mais protegida. Nesse caso, as curvas dos sedimentos da parte norte exibem uma população por saltação muito bem selecionada e composta unicamente de partículas na faixa granulométrica de 0,25 a $0,5 \mathrm{~mm}$. Na parte sul, a população por saltação das curvas passa a incorporar partículas com diâmetros de 0,25 a $0,062 \mathrm{~mm}$, com o conseqüente empobrecimento da seleção; 2 . aumento da população por suspensão, que compreende a fração granulométrica inferior a $0,062 \mathrm{~mm}$. Essa população, praticamente ausente nos sedimentos do estirâncio do setor I (porcentagens inferiores a $0,02 \%$ ), pode atingir porcentagens de até $5 \%$ no setor III. Para condições hidráulicas, essas variações no padrão das curvas granulométricas refletem uma diminuição da turbulência e, portanto, da eficiência da ação de joeiramento, conduzindo à acumulação cada vez maior da fração mais fina e/ou aumento da população por suspensão.

As curvas granulométricas dos sedimentos da antepraia (Figs. 3A, B e C) separam-se em dois grupos distintos. O primeiro, formado pelas amostras dos setores I e II, mostra uma população por saltação bem desenvolvida e que inclui as partículas na faixa granulométrica entre 0,25 e $1 \mathrm{~mm}$. As populações por rolamento/arrasto e por suspensão ocorrem em porcentagens inferiores a 10 e 1\%, respectivamente. Essas características das curvas são um reflexo do nível relativamente alto da turbulência, com forte movimentação da água, capaz de eliminar a maior parte do material com diâmetro de até $0,25 \mathrm{~mm}$. O segundo grupo de curvas, representativo das amostras do setor III, é caracterizado pela presença, em proporções mais ou menos equivalentes, das populações por saltação e por suspensão. Ambas são pobremente selecionadas, com a população por saltação englobando as partículas na faixa granulométrica de 1 a $0,062 \mathrm{~mm}$; a população por suspensão é representada pelo material com granulometria inferior a essa faixa. Essas características espelham as condições de fraca turbulência que possibilitam a deposição de grande parte do material lamoso, transportado por suspensão.

De um modo geral, a população por rolamento/arrasto é pouco desenvolvida nos sedimentos da área estudada, constitu- 
indo, comurnente, menos de 10\% do total de sua distribuição granulométrica. As proporções e características dessa população não mostram, aparentemente, nenhuma associação com as variações da energia ao longo da área sendo, mais provavelmente, determinada pelas características texturais do material fornecido pela rocha fonte.
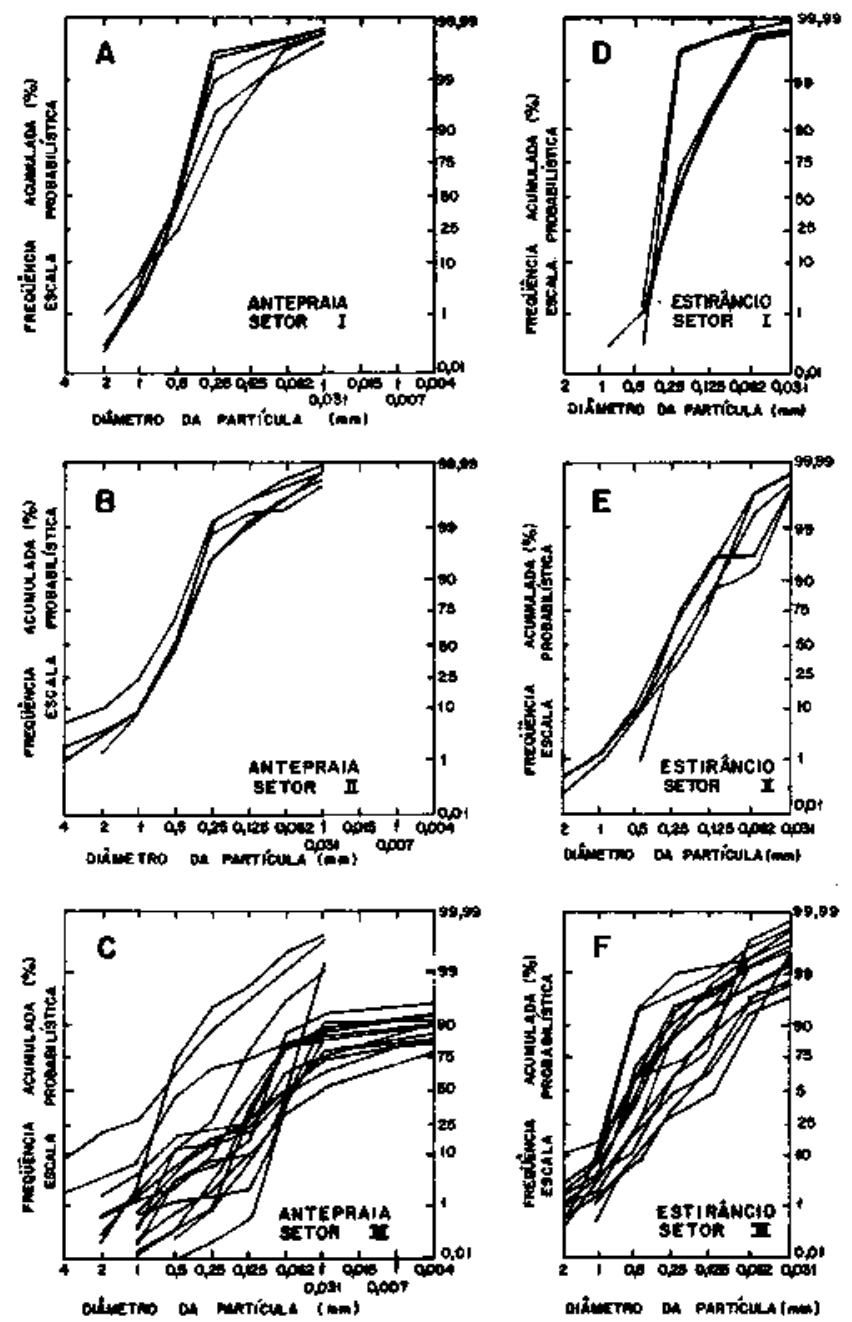

Figura 3 - Curvas granulométrícas cumulativas dos sedimentos

Figure 3 - Cumulative grain size frequence curves of the sediments

Mediana Para a totalidade das amostras analisadas, os valores máximo e mínimo observados da mediana foram, respectivamente, 0,870 e $0,023 \mathrm{~mm}$.

Nos sedimentos do estirâncio a distribuição dos valores da mediana, que estão compreendidos entre 0,110 e $0,870 \mathrm{~mm}$, parece depender muito mais das características da rocha fonte do que das variações das condições de energia (Fig. 4). Efetivamente, não se observa nenhuma variação sistemática que possa ser associada, por exemplo, com a diminuição gradativa da energia das ondas do setor I para os setores II e III. Por outro lado, os valores mais altos observados são encontrados na parte sul do setor III, no trecho compreendido entre a localidade de Periperi e a ponta da Sapoca (Fig. 1), onde a energia é, portanto, menos intensa do que nos outros dois setores. Esses valores mais altos da mediana resultam da presença, nos sedimentos desse trecho, de uma maior proporção de grãos com granulometria superior a $0,25 \mathrm{~mm}$, em comparação com os setores I e II. Ao longo do estirâncio, a turbulência da água promove a eliminação total do material com granulometria inferior a $0,031 \mathrm{~mm}$ e, em alguns casos, de parte das partículas na faixa granulométrica entre 0,031 e 0,25 mm. Desse modo, a presença, nos sedimentos ali depositados, de maior ou menor proporção de grãos com diâmetro superiores a $0,25 \mathrm{~mm}$, não está, obviamente, associada ao nível de energia de um determinado trecho, estando, muito mais provavelmente, relacionada com a maior ou menor disponibilidade dessas partículas na rocha fonte, que é o principal fator controlando a distribuição da mediana no estirâncio.

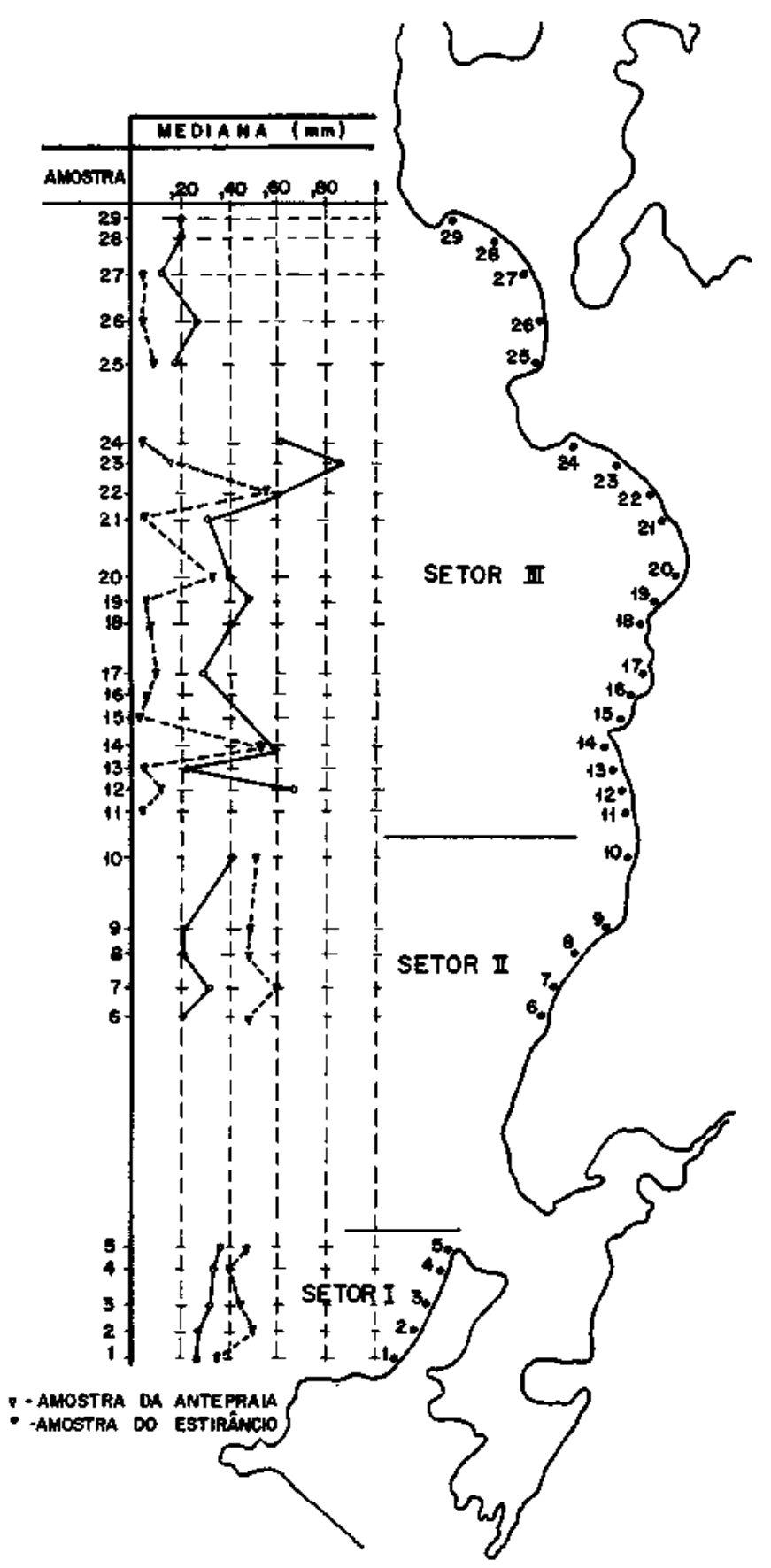

Figura 4 - Distribuição da mediana na área estudada Figure 4 - Median distribution in the studied area

Na faixa da antepraia dos setores I e I I (Fig. 4), os valores observados da mediana são superiores a $0,35 \mathrm{~mm}$. A forte turbulência da água nessa faixa promove uma intensa ação 
de joeiramento que elimina a maior parte do material com granulometria de até $0,25 \mathrm{~mm}$. Dessa forma, os valores da mediana dos sedimentos aí depositados dependem, fundamentalmente, das características da distribuição granulométrica do material com diâmetro superior a esse tamanho, fornecido pela rocha fonte. Na região da antepraia do setor III (Fig. 4), as medianas são inferiores a $0,120 \mathrm{~mm}$, refletindo a presença nos sedimentos de grande quantidade de material lamoso, cuja deposição é favorecida pelas condições de turbulência muito fraca.

As diferenças de nível da turbulência existentes entre as regiões da antepraia e do estirâncio em cada setor, ao longo da área, refletem-se sobre os valores relativos da mediana. Assim, nos setores I e I I (Fig. 4), os sedimentos da antepraia têm medianas que são sistematicamente maiores do que no caso do estirâncio, ocorrendo o inverso no setor III (Fig. 4). O aumento gradativo da energia das ondas, que ocorre ao longo do setor I, no sentido de sul para norte, é, ao que tudo indica, o principal fator determinante do aumento correspondente da mediana, ali observado (Fig. 4).

Desvio Padrão ( $\boldsymbol{\sigma} \boldsymbol{\varnothing}$ ) Para a totalidade das amostras analisadas, os valores máximo e mínimo observados do desvio padrão foram, respectivamente, 0,188 e 3,3 0. Esses valores limitam uma faixa de distribuição do desvio padrão muito mais ampla do que a estabelecida por Friedman (1962), para as areias de praia em geral $(0,35<\sigma \varnothing<0,50)$, ou por Nordstron (1977) para os sedimentos de praias com níveis de energia muito alto e moderado $(0,37<\sigma \varnothing<0,48)$.

Folk \& Ward (1957), Friedmann (1962), Wood (1964), Brambati (1969) e Bigarella et al (1969) observam que o selecionamento, no caso de sedimentos arenosos, é melhor para a faixa granulométrica de areia fina a média. $\mathrm{Na}$ área estudada, o gráfico da figura 5 mostra que o desvio padrão é independente da mediana, para valores dessa última compreendidos entre 0,2 e $0,6 \mathrm{~mm}$. Para valores abaixo de $0,2 \mathrm{~mm}$, o desvio padrão cresce com a diminuição da mediana. Nesse caso, o comportamento do desvio padrão, vis-à-vis da mediana, está relacionado com a presença nos sedimentos, da fração granulométrica inferior a $0,031 \mathrm{~mm}$, que tende a aumentar os valores do primeiro, resultando em um empobrecimento da seleção. Essa fração granulométrica ocorre, em porcentagens acima de $1 \%$, unicamente nos sedimentos da região de baixa energia, correspondente à antepraia do setor III, onde foi coletada a quase totalidade das amostras com medianas inferiores a $0,2 \mathrm{~mm}$. Os valores do desvio padrão correspondentes a essas amostras são superiores a $1 \varnothing$, caracterizando um selecionamento de pobre a muito pobre (Fig. 6).
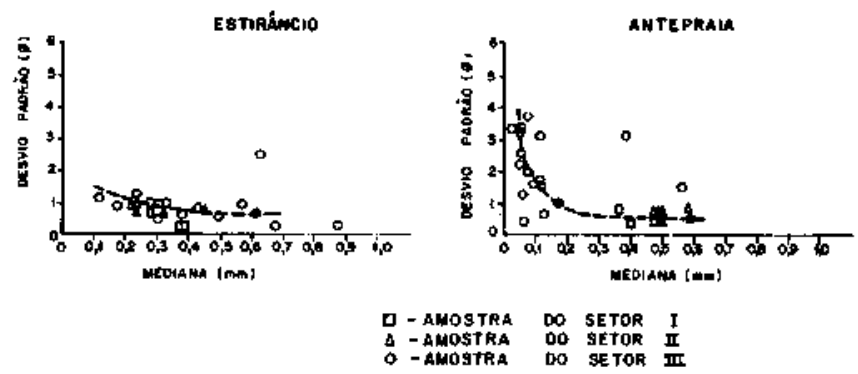

Figura 5 - Relação entre o desvio-padrão e a mediana para as amostras do estirâncio e da antepraia

Figure 5 - Plots of standard deviation against median for the foreshore and shoreface sediments

Na região da antepraia dos setores I e II, e ao longo de toda faixa do estirâncio da área estudada, a distribuição granulométrica dos sedimentos está praticamente limitada à faixa entre 0,031 e $2 \mathrm{~mm}$. O limite inferior é determinado pelo nível de turbulência da água, que não permite a sedimentação de partículas lamosas. O limite de $2 \mathrm{~mm}$ para a granulometria das partículas mais grossas é, evidentemente, uma característica condicionada pela rocha fonte. Os valores observados para o desvio padrão das amostras estão compreendidos, na sua grande maioria, entre 0,5 e $1 \varnothing$, correspondendo a um selecionamento moderado (Fig. 6). Não são verificadas, portanto, variações significativas no desvio padrão que possam caracterizar as variações da intensidade da turbulência da água, ao longo das regiões em questão.

$\mathrm{Na}$ faixa do estirâncio do setor I (Fig. 6), os sedimentos da zona mais exposta à ação das ondas, ao norte, apresentam um selecionamento muito bom. Na parte sul desse setor, menos exposto, os sedimentos dessa mesma faixa têm selecionamento de bom a moderado.

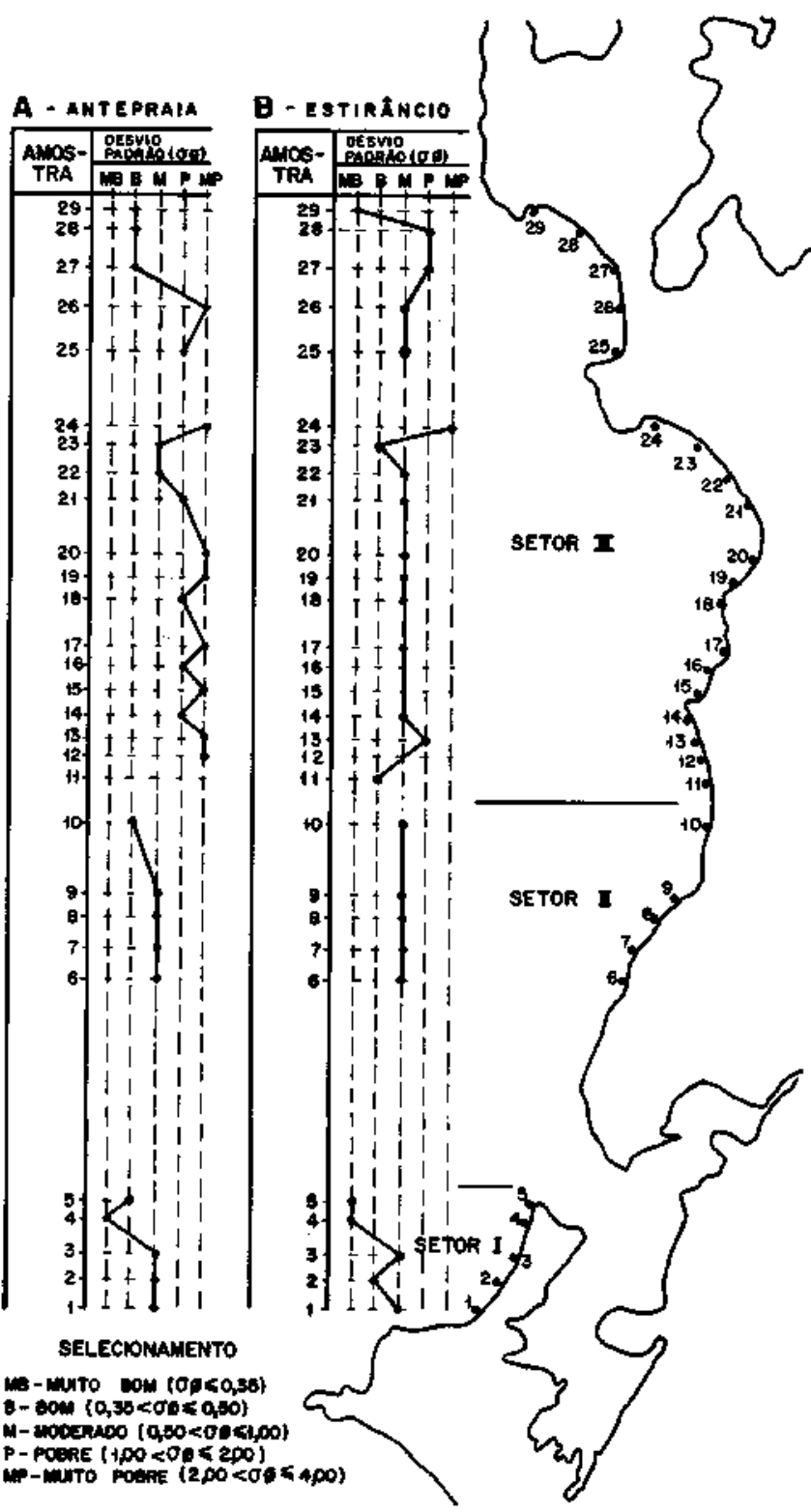

Figura 6 - Distribuição do desvio-padrão na área estudada Figure 6 - Standard deviation distribution in the studied area

Assimetria (SKI) Os valores máximo e mínimo observados da assimetria foram, respectivamente, +0,75 e -0,656, com uma grande dominância de distribuições granulométricas simétricas $(-0,10<\mathrm{SKI}<0,10)$ e assimétricas positivas/muito 
positivas (SKI > 40,10) e, em menor proporção, assimétricas negativas/muito negativas (SKI $<-0,10)$. Esses resultados são discordantes das observações de Duane (1964) e Friedmann $(1967,1979)$ de que os sedimentos praiais apresentam característicamente distribuições simétricas e assimétricas negativas/ muito negativas $(\mathrm{SKI}<40,10)$ características.

Com base na análise da distribuição da assimetria ao longo da área (Fig. 7), é possível distinguir, a grosso modo, as diversas regiões com diferentes níveis de energias das ondas, a saber 1. região da antepraia dos setores I e II. Os sedimentos têm distribuições granulométricas negativas/muito negativas, com um único caso de distribuição simétrica. Isso reflete a concentração da fração granulométrica grossa, promovida pela forte turbulência da água, que elimina totalmente a fração lamosa e parte das partículas com granulometria na faixa de 0,031 e $0,25 \mathrm{~mm} ; 2$. região abrangendo toda a faixa do estirâncio, onde os sedimentos apresentam predominantemente distribuições granulométricas simétricas, seguidas de assimétricas positivas/muito positivas e, em raros casos, assimétricas negativas e muito negativas. Essas características das distribuições granulométricas estão em consonância com a ação mais moderada de joeiramento, suficiente, entretanto, para eliminar todo excesso da fração granulométrica mais fina, representada pelas partículas com diâmetro inferior a 0,031 $\mathrm{mm}$; 3. região da antepraia do setor III, onde dominam assimetrias muito positivas/positivas, com raras ocorrências de distribuições granulométricas simétricas ou assimétricas negativas/muito negativas. Os valores da assimetria refletem, destarte, as condições de fraca turbulência que possibilitam a incorporação, na distribuição granulométrica dos sedimentos, de um excesso significativo de partículas lamosas.

As diferenças de nível de energia entre as faixas do estirâncio e da antepraia, que ocorrem em cada setor, são também refletidas no comportamento da assimetria, analogamente ao que acontece com a mediana. $\mathrm{O}$ gráfico relacionando esses dois parâmetros (Fig. 8) mostra que nos setores I e II, nos quais a energia é maior na antepraia, as amostras dessa última, com valores relativamente altos da mediana e assimetrias negativas, são separadas das do estirâncio, com medianas menores e assimetrias positivas. No setor III, onde a turbulência é mais forte no estirâncio, embora exista uma maior dispersão dos pontos, ainda é possível observar uma nítida tendência de separação das amostras do estirâncio com medianas mais grossas e distribuições simétricas ou assimétricas negativas- daquelas da antepraia, com medianas mais finas e distribuições assimétricas positivas ou muito positivas.

No setor I, os sedimentos do estirâncio da parte sul, mais protegida da ação das ondas, têm assimetrias positivas. Na parte norte, mais exposta, os sedimentos dessa faixa apresentam distribuições granulométricas simétricas (Fig. 7).

Imagem granulométrica A imagem granulométrica de um depósito sedimentar, conceito introduzido por Passega \& Byranjee (1969), é representada pelo conjunto dos diagramas C-M, F-M, L-M e A-M. O C representa a granulometria correspondente ao percentual de $1 \%$ na curva granulométrica. $\mathrm{O}$ M representa a mediana; F, L e A, correspondem, respectivamente, às porcentagens em peso das frações granulométricas inferiores a 0,125,0,031 e 0,004 mm, presentes no sedimento. Segundo Passega \& Byranjee (1968), a imagem granulométrica fornece informações bem precisas sobre as condições hidráulicas de formação de um depósito sedimentar elástico.

$\mathrm{Na}$ área estudada, o diagrama $\mathrm{C}-\mathrm{M}$ dos sedimentos do estirâncio (Fig. 9D) exibe um padrão que se alinha paralelamente ao limite $\mathrm{C}=\mathrm{M}$, em correspondência ao segmento $\mathrm{QR}$ de Passega $(1957,1964)$ e indicativo de um transporte dominante por suspensão gradada (termo equivalente à saltação de Visher 1969 ou à suspensão intermitente de Middleton \& Southard 1984). No diagrama da figura 9B, o valor de M para $\mathrm{F}=20 \%$ é de aproximadamente $0,2 \mathrm{~mm}$. Os valores de $\mathrm{L}$ são

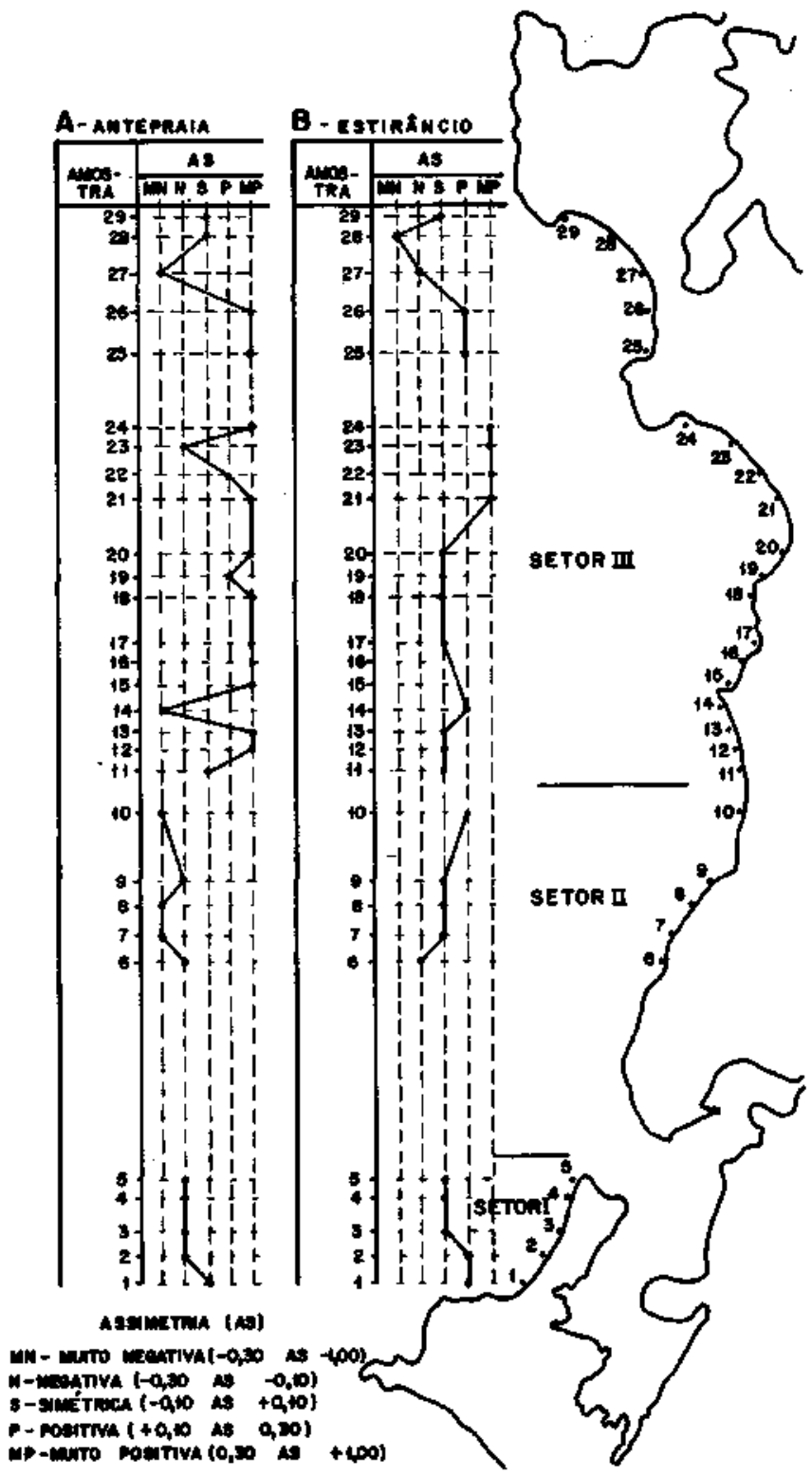

Figura 7 - Distribuição da assimetria ao longo da área Figure 7 - Skewness distribution in the studied area

muito baixos e A está ausente em todas as amostras analisadas. Os sedimentos do estirâncio apresentam, dessa maneira, uma imagem granulométrica característica de depósitos praiais, nos quais o transporte por suspensão gradada é dominante e a ação de joeiramento tem um papel preponderante. $\mathrm{O}$ valor de 0,2 $\mathrm{mm}$ da mediana, para $\mathrm{F}=20 \%$ indica, entretanto, que eles são mais pobremente selecionados do que os depósitos praiais típicos, cujas medianas para esse mesmo valor de $\mathrm{F}$, apresentam valores próximos a 0,15 mm (Passega \& Byranjee 1969). $\mathrm{O}$ diagrama C-M das amostras da antepraia da área estudada (Fig. 9C) mostra dois conjuntos distintos de agrupamento de pontos. O primeiro, constituído quase que totalmente pelas amostras dos setores leu, forma um padrão alongado disposto verticalmente, paralelo à ordenada representativa de $\mathrm{C}$ e correspondente ao segmento PQ de Passega $(1957,1964)$. Esse padrão é característico de depósitos de suspensão gradada, com uma pequena porção de grãos rolados, que não afeta o valor da mediana. $\mathrm{O}$ segundo conjunto, formado unicamente por amostras do setor III, mostra um padrão de pontos dispersos situados, à exceção de um único ponto, acima da Unha $\mathrm{C}=0,2 \mathrm{~mm}$. Ele tipifica depósitos formados por misturas de grãos transpor- 


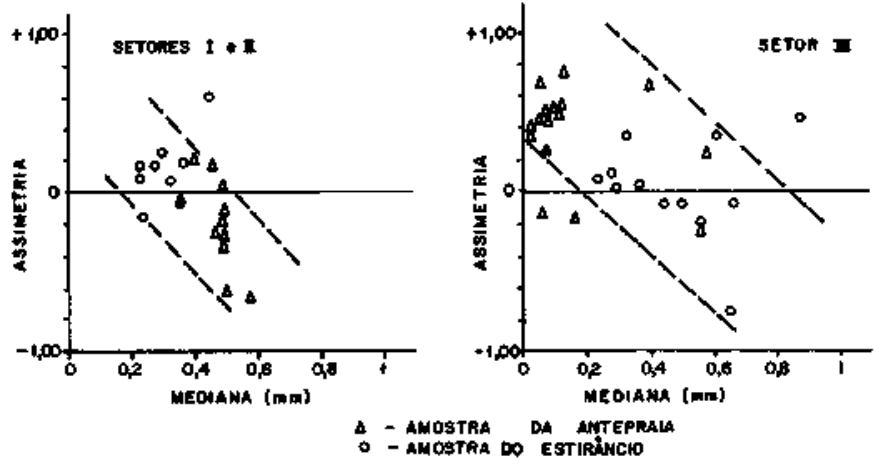

Figura 8 - Relação entre a assimetria e a mediana na área estudada

Figure 8 - Plots of skewness against median for the sediments on the studied area

tados por suspensão gradada, suspensão uniforme e rolamento. $\mathrm{O}$ diagrama da figura 9A mostra que para os valores da mediana acima de $0,3 \mathrm{~mm}$, correspondentes a amostras dos setores I e II, os valores de F são inferiores a $6 \%$, enquanto L e A estão totalmente ausentes. Isso reflete a alta turbulência, com forte ação de joeiramento que elimina praticamente todo material com granulometria inferior a $0,125 \mathrm{~mm}$. Para os valores da mediana inferiores a $0,3 \mathrm{~mm}$, que correspondem às amostras do setor $\mathrm{m}$, os valores de $\mathrm{F}, \mathrm{L}$ e $\mathrm{A}$, crescem rapidamente, à medida que a mediana diminui, evidenciando uma diminuição da intensidade da turbulência e conseqüentemente da capacidade de eliminação da fração granulométrica inferior a $0,125 \mathrm{~mm}$.

A partir do diagrama C-M, Passega \& Byranjee (1969) propuseram uma subdivisão dos sedimentos elásticos em nove classes, distinguidas de acordo com os mecanismos de transporte e deposição dominantes. Na área estudada, os sedimentos do estirâncio pertencem, na sua grande maioria, a duas dessas classes, (Fig. 9D), a saber: 1. Classe I, que engloba as amostras dos setores II e HI, no qual o transporte é dominantemente por suspensão gradada, com uma pequena proporção de grãos grossos rolados; 2. Classe IV, na qual se inserem as amostras do setor I, cujo transporte é unicamente por suspensão gradada. Ao que tudo indica, a ausência de grãos rolados nos sedimentos do estirâncio do setor I e a presença dos mesmos nos sedimentos dessa mesma faixa nos setores II e III, não se relaciona com as condições de energia, muito mais forte nesse primeiro setor do que nos outros dois. Isso parece depender muito mais da disponibilidade desses grãos no material fornecido pela rocha fonte, o que estaria de acordo com as observações de Middleton \& Southard (1984) de que a quantidade e as propriedades da população de tração em um depósito sedimentar são limitadas pelas condições de disponibilidade da rocha fonte com pouca influência das condições hidráulicas.

$\mathrm{Na}$ antepraia (Fig. 9C) os sedimentos dos setores I e I I pertencem à classe I, que reflete um transporte dominantemente por suspensão gradada, com uma pequena porcentagem de grãos rolados. Nesse caso, esses grãos parecem constituir um material residual, concentrado em locais de alta turbulência, associados à arrebentação das ondas. As amostras do setor III pertencem, na sua grande maioria, à classe III e, em menor proporção, à classe $\mathrm{V}$, caracterizando sedimentos transportados dominantemente por suspensão uniforme (classe III) ou gradada (classe V) e que podem conter grãos rolados maiores do que $1 \mathrm{~mm}$.

DISCUSSÕES E CONCLUSÕES Ao longo da faixa praial da costa leste da Bafa de Todos os Santos, ocorrem variações significativas da energia das ondas, que têm ampla repercussão nas características texturais e composicionais nos sedimentos aí depositados.
Com base no nível de energia das ondas, podem ser distinguidas, no trecho praial estudado, as seguintes zonas: 1. zonas de energia relativamente alta, englobando a faixa da antepraia dos setores I e II, e a parte norte da região do estirâncio do setor I; 2. zonas de energia moderada, compreendendo a faixa do estirâncio dos setores I e $\mathrm{n}$ e a parte sul da região do estirâncio do setor I; 3. zona de baixa energia, representada pela faixa da antepraia do setor in.

Texturalmente, as curvas granulométricas constituem um dos elementos mais efetivos na caracterização dos sedimentos das diferentes zonas acima definidas. Muito embora a dominância da população por saltação seja uma característica comum à grande maioria das curvas analisadas, o padrão apresentado por cada uma delas está intimamente associado com o nível de energia e com a intensidade da turbulência do ambiente. Assim, nas zonas de energia relativamente alta, a forte ação de joeiramento elimina praticamente todo o material com granulometria inferior a $0,25 \mathrm{~mm}$. Nas curvas granulométricas dos sedimentos dessas zonas, a população por saltação constitui mais de $99 \%$ do total da distribuição granulométrica, sendo composta por partículas com diâmetro superior a esse tamanho. O material com granulometria inferior a $0,25 \mathrm{~mm}$ ocorre em porcentagens sempre inferiores a $1 \%$ e é transportado por suspensão. Nas zonas de energia moderada, a turbulência do meio aquoso é suficientemente intensa apenas para não permitir a sedimentação de partículas com diâmetro inferior a $0,031 \mathrm{~mm}$. As curvas granulométricas dos sedimentos aí depositados são caracterizados por uma população por saltação que inclui partículas com granulometria superior a esse valor, sendo, portanto, mais pobremente selecionada do que no caso dos sedimentos das zonas de energia relativamente alta. $\mathrm{Na}$ zona de baixa energia, a turbulência é muito fraca e a ação de joeiramento pouco efetiva. As curvas granulométricas exibem, na sua quase totalidade, uma população por suspensão que pode atingir até mais de $50 \%$ do total da distribuição granulométrica, compreendendo partículas com tamanho inferior a $0,031 \mathrm{~mm}$.

A imagem granulométrica mostrou-se eficiente apenas para distinguir os sedimentos da zona de baixa energia daqueles das zonas onde esta é alta ou moderada. Ela não permitiu uma separação mais efetiva entre os sedimentos dessas duas últimas zonas.

Os parâmetros sedimentares estatísticos, em seus valores absolutos, não se demonstraram suficientemente eficazes na distinção dos sedimentos depositados nas diferentes zonas, com níveis distintos de energia, da área estudada. Em termos relativos, a assimetria foi, dentre os parâmetros analisados, o que se mostrou mais eficiente na caracterização desses sedimentos. Desse modo, nas zonas de energia relativamente alta predominam sedimentos com distribuições assimétricas negativas/muito negativas, com a ocorrência em menor proporção de distribuição simétricas. Onde a energia é moderada, predominam distribuições simétricas, seguidas das assimétricas positivas/muito positivas e, muito raramente, assimétricas negativas/muito negativas. Nas zonas de baixa energia, as distribuições granulométricas dos sedimentos são dominantemente positivas/muito positivas, com raros casos de distribuições simétricas ou assimétricas negativas/muito negativas.

A mediana e o desvio padrão são fortemente influenciados pelas características granulométricas do material fornecido pela rocha fonte, tendo-se mostrado pouco eficientes, mesmo em termos relativos, para distinguir os sedimentos depositados nas zonas de alta, moderada e baixa energia. Entretanto, de modo aparentemente paradoxal, esses dois parâmetros, e a assimetria, revelaram-se bastante sensíveis às diferenças de nível de energia, existentes entre as regiões da antepraia e estirâncio, em cada setor individual da área. No caso dos setores I e $\mathrm{u}$, nos quais a energia das ondas é maior na antepraia, os sedimentos dessa região têm medianas mais grossas, são mehoresselecionados e apresentam menores valores da assimetria 


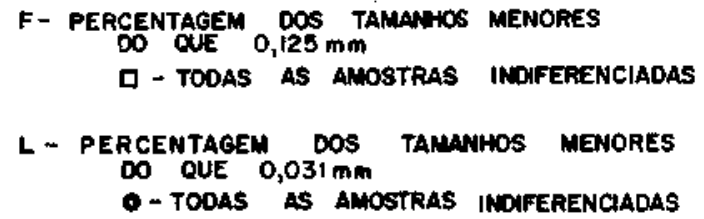

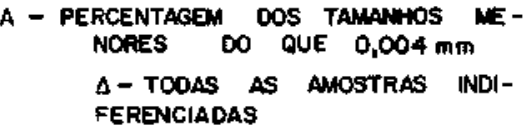

A

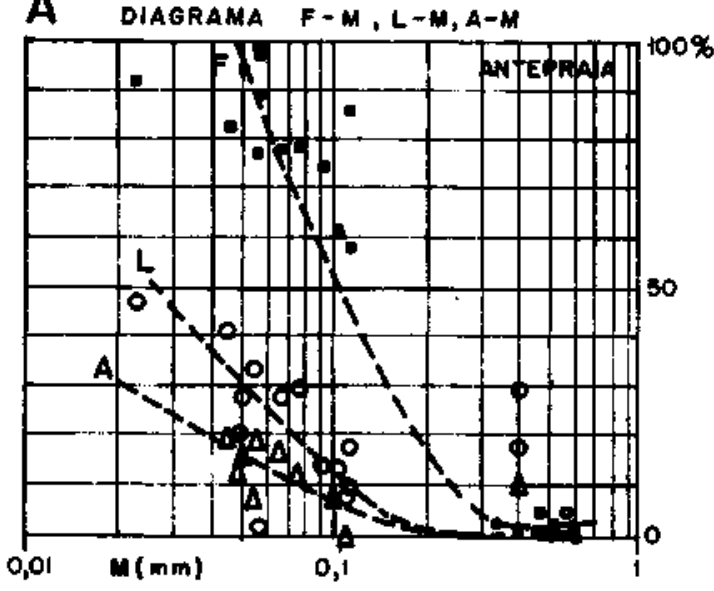

C

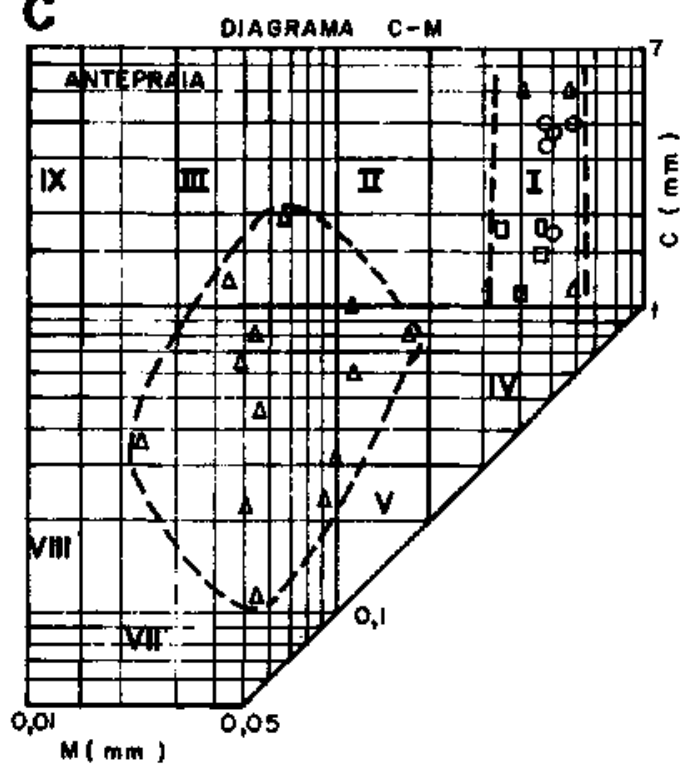

B DIAGRAMA F-M, L-M, A-M

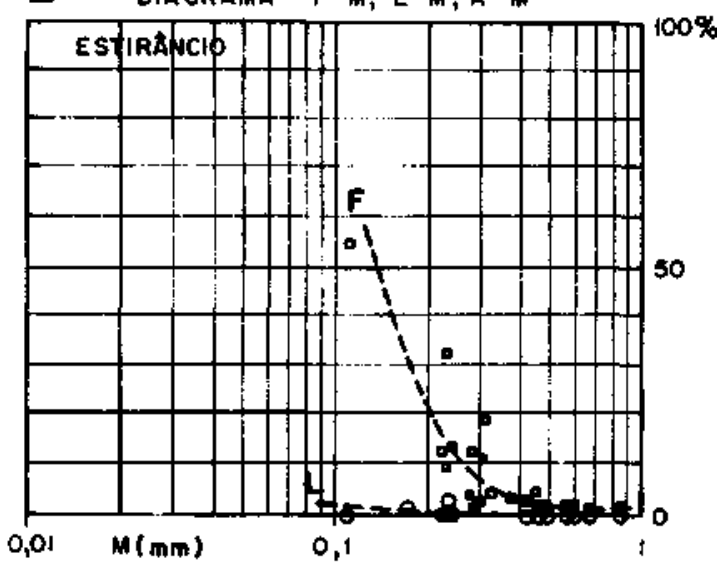

D

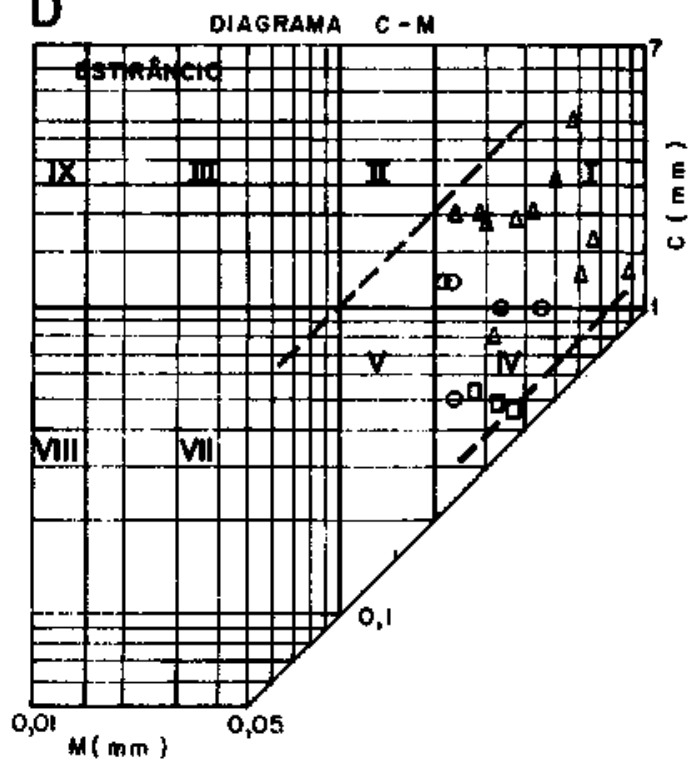

Figura 9 - Imagem granulométríca dos sedimentos do estirâncio e da antepraia Figure 9 - Grain-size image for the foreshore and shoreface sediments

do que os do estirâncio, onde a energia é menor. No setor III, contrariamente ao que acontece nos outros dois setores, a ação das ondas é mais efetiva no estirâncio do que na antepraia, o comportamento relativo desses parâmetros se inverte. Relações similares são também observadas ao longo do estirâncio do setor I, na diferenciação dos sedimentos depositados na parte sul do mesmo, mais protegida da ação das ondas, daqueles da parte norte, mais exposta. Esse comportamento dos parâmetros sedimentares estatísticos parece indicar que as variações maiores nas características texturais do material fornecido pela rocha fonte, ao ponto de terem uma influência determinante sobre os valores relativos desses parâmetros, ocorrem, sobretudo, de setor para setor, ao longo da área. A própria compartimentação da faixa litorânea estudada, situada dentro de um mesmo contexto climático, em setores com diferentes características fisiográficas, pode ser, em grande parte, uma expressão dessas variações. Dentro de cada setor individual, com variações menos significativas nas características da rocha fonte, os valores relativos dos parâmetros sedimentares sofreriam, então, forte influência das variações das condições de energia.

Sobre os atributos composicionais dos sedimentos, o nível de energia ambiental é um parâmetro fundamental que contro- 
la a quantidade de fragmentos esqueletais carbonáticos presentes nesses sedimentos. As condições de restrição e de fraca agitação das águas que caracterizam as regiões mais internas da baía favorecem o desenvolvimento dos organismos, sendo generalizada a ocorrência, no fundo da mesma, de concheiros e bancos de corais, que são extensivamente explorados por indústrias de fabricação de cimento ali instaladas. Nas regiões mais próximas à entrada da baía, a movimentação no fundo, por força das correntes de maré, inibe sobremaneira o desenvolvimento dos organismos marinhos que vivem no fundo da mesma. Essas relações entre a energia do ambiente e o desenvolvimento dos organismos refletem-se na composição dos sedimentos praiais da área estudada, cuja quantidade de partículas carbonáticas tem um aumento exponencial a partir das praias próximas da região de entrada da baía para aquelas situadas mais para o seu interior.

Comparados com os depósitos praiais da orla oceânica de Salvador, mais exposta à ação de ondas com mais energia, os sedimentos da costa leste da Baía de Todos os Santos mostramse muito mais ricos em componentes esqueletais carbonáticos, refletindo as condições gerais de maior restrição e de menor turbulência das águas no interior da baía. Nas areias da orla oceânica, as porcentagens desses componentes raramente ultrapassam os 25\% (Bittencourt 1975). Nas praias da costa leste da baía, elas podem alcançar até mais de $75 \%$, sobretudo nas regiões mais interiores da mesma. As diferenças das condições de exposição e de energia das ondas entre as duas faixas praiais em questão, não somente influenciam a quantidade como também se reflete na natureza dos fragmentos de organismos presentes nos sedimentos. Desse modo, as algas Halimeda, cujos esqueletos calcários são relativamente frágeis, ocorrem de maneira generalizada nos sedimentos praiais da costa leste da baía. Esses são encontrados muito raramente nas areias das praias da orla oceânica, onde são substituídos por fragmentos de algas coralinas, mais adaptadas às condições gerais de alta energia aí reinantes. Ainda nos sedimentos praiais da orla oceânica, os foraminíferos estão presentes em porcentagens, em alguns casos, superiores a $25 \%$ do total de componentes esqueletais. Nos sedimentos da faixa praial da costa leste da baía, eles ocorrem em porcentagens inferiores a 5\%. O trabalho de Bittencourt (1975) mostra que os sedimentos praiais da orla oceânica de Salvador apresentam, comumente, curvas granulométricas caracterizadas por uma ampla dominância da população por saltação, que constitui mais de $95 \%$ do total da distribuição granulométrica, englobando partículas na faixa granulométrica entre 0,25 e $1 \mathrm{~mm}$. A fração granulométrica inferior a $0,25 \mathrm{~mm}$, que corresponde à população por suspensão, ocorre em porcentagens inferiores a $3 \%$. A população por rolamento, que abrange as partículas com diâmetros superiores a $2 \mathrm{~mm}$, aparece em porcentagens inferiores a $1 \%$. Os valores da mediana estão compreendidos entre 0,1 e $0,9 \mathrm{~mm}$, o selecionamento é de bom a muito bom. As distribuições granulométricas são predominantemente simétricas, com igual número de assimétricas negativas e muito negativas. A imagem granulométrica apresenta um padrão que caracteriza um transporte dominante por suspensão gradada, típica de depósitos praiais. Esses sedimentos são, assim, para a granulometria, muito semelhantes àqueles encontrados nas regiões de alta energia da faixa praial da costa leste da baía. Essa semelhança reflete uma similaridade dos processos de transporte e deposi- ção atuantes nessas regiões, onde a turbulência da água é intensa e a ação do joeiramento tem importância fundamental. Segundo Bittencourt (1975), existem trechos ao longo da faixa praial da orla oceânica de Salvador em que a costa apresenta reentrâncias mais acentuadas ou nos quais o declive da antepraia é muito baixo, de modo que, a energia das ondas é bastante atenuada. Nesses trechos, os sedimentos apresentam características granulométricas similares ao observado nas regiões de energia moderada da costa leste da baía de Todos os Santos.

Nos últimos anos, após a coleta das amostras estudadas neste trabalho em maio de 1988, tem havido um aumento crescente, nos sedimentos praiais da costa leste da Baía de Todos os Santos, da quantidade de partículas carbonáticas, em particular de fragmentos de coral, com granulometria na faixa de areia até bloco, como resultado da desagregação e do quebramento intenso dos bancos de coral e dos depósitos conchíferos existentes no fundo da baía, em decorrência da intensa exploração desse material pelas indústrias de cimento ali instaladas. Além do irreparável dano ecológico e de modificações nas características composicionais e texturais dos sedimentos, o aumento no suprimento de sedimento decorrente de tal ação vem causando um crescimento acentuado do volume de sedimento acumulado em algumas praias, notadamente na região de São Tome de Paripe.

Em conclusão, as características composicionais e granulométricas dos sedimentos praiais da área estudada são fortemente influenciadas pelas condições de energia ambiental. Em termos absolutos, foi possível caracterizar, a partir da análise das curvas granulométricas, zonas com níveis distintos de energia, a saber: 1. zonas de alta energia - correspondem a regiões nas quais a turbulência é intensa o bastante para promover o transporte por suspensão de partículas com diâmetros de até $0,25 \mathrm{~mm} ; 2$. zona de energia moderada - a turbulência é suficientemente intensa para não permitir a sedimentação de partículas com diâmetros inferiores a $0,031 \mathrm{~mm}$. O material com diâmetro entre 0,031 e $2 \mathrm{~mm}$ é transportado essencialmente por saltação; 3. zona de baixa energia a fraca turbulência possibilita a sedimentação de partículas lamosas. As características composicionais e os parâmetros estatísticos dos sedimentos mostraram-se grandemente afetados pelas variações da energia dentro de setores ou zonas mais restritas, nos quais as características texturais da rocha fonte são relativamente homogêneas. À luz dos resultados obtidos e tendo em mente as limitações do uso de características granulométricas na interpretação das condições de deposição de sedimentos antigos, é possível que se possa utilizar essas características para tentar reconhecer, em antigos depósitos praiais, segmentos depositados em condições de maior ou menor energia. Eventualmente, isso poderá ter alguma utilidade, até mesmo econômica, como por exemplo, na caracterização de zonas mais favoráveis à ocorrência de depósitos de pláceres. Por outro lado, os dados resultantes deste trabalho poderão servir como referência para o acompanhamento e avaliação de possíveis modificações e interferências no meio ambiente, em conseqüência da ação antrópica.

Agradecimentos Os autores agradecem ao prof. Olivar A.L. Lima pela versão do resumo para o inglês. Agradecimentos são extensivos a Natanael P. Gomes pela confecção dos desenhos e a Malviene T. Cardoso pela digitação do texto.

\section{REFERÊNCIAS BIBLIOGRÁFICAS}

SECRETARIA DAS MINAS E ENERGIA 1975. Projeto Argila no Recôncavo Baiano - Relatório Final. v. 1 (Texto). Bahia, SME/CAM. 160 p. BIGARELLA, J.J.; ALESSI, A.H.; BECKER, R.D.; DUARTE, G.M. 1969. Textural characteristics of the coastal dune, sand ridge and beach sediments. Bol. Paran. Geoc., 27:80 p.

BITTENCOURT, A.C.S.P. 1975. Sedimentação recente na costa atlântica de Salvador. Rev. Bras. Geoc., 5:46-63.
BITTENCOURT, A.C.S.P.; VILAS BOAS, G.S.; FLEXOR, J.M.; MARTIN, L. 1979. Geologia dos depósitos quaternários no litoral do Estado da Bahia. In: INDA, H. ed., Geologia e Recursos Minerais do Estado da Bahia. Salvador, SME/CPM. p. 452-464. (Textos Básicos 1).

BRAMBATI, A. 1969. Sedimentazione recente nelle lagune di Marano e di Grado (Adriático Settentrionale). Riv. Museo Trid. Sei. Nat., XLVI(1): 142-239. 
CONCEIÇÃO, T.M.L. 1973. Alteração de Rochas e Sedimentos da Parte Ocidental do Recôncavo Baiano. Salvador. 130 p. (Tese Professor Assistente, IG/UFBA).

DUANE, D.B. 1964. Significance of skewness in recent sediments, Western Pamlico. Sound, North Carolina. J. Sed. Petrol., 34:864-874.

FOLK, R.L. \& WARD, W.C. 1957. Brazos River bar: a study in the significance of grain size parameters. J. Sed. Petrol, 27:3-26.

FRIEDMAN, G.M. 1962. On sorting, sorting coefficients and the grain size distribution of sandstones. J. Sed. Petrol, 13:233-252

FRIEDMAN, G.M. 1967. Dynamic processes and statistical parameters compared for size frequency distribution of beach and river sands. J. Sed. Petrol, 37:327-354.

FRIEDMAN, G.M. 1979. Differences in size distributions of populations of particles among sands of various origins. Sedimentology, 26:3-32.

INDA, H.A.V. \& BARBOSA, J.S.F. 1978. Texto Explicativo para o Mapa Geológico do Estado da Bahia - Esc. 1:1.000.000. Salvador, SME/ CPM. 13 p.

MARTIN, L: BITTENCOURT, A.C.S.P - VILAS BOAS, G.S ; FLEXOR, J.M. 1980. Mapa Geológico do Quaternário Costeiro do Estado da Bahia $\bullet$ Texto Explicativo. Salvador, SME/CPM. 57 p.

MIDDLETON, G.V. \& SOUTHARD, J.B. 1984. Mechanics of Sediment Movement. 2 ed. SEPM. 401 p. (Short Course 3).

NORDSTROM, K.F. 1975. Beach Response Rates to Cyclic Waves Regimes at Dandy Hook, New Jersey. Rutgers, Rutgers University, Marine Scienses Center. (Techinical Report 75-3).

NORDSTROM, K.F. 1977. The use of grain size statistics to distinguish between high-and-moderate-energy beach environments. J. Sed. Petrol, 47:1287-1294.
PASSEGA, R. 1957. Texture as characteristics of clastic deposits. Bull. Am. Ass. Petrol Geol, 42:1952-1984.

PASSEGA, R. 1964. Grain size representation by CM patterns as a geological tool. J. Sed. Petrol, 34:830-847.

PASSEGA, R. \& BYRAMJEE, R. 1969. Grain size image of clastic deposits. Sedimentology, 13:233-252.

SESTINI, G. 1967. Textura! characters of Salvador beach sands. Boi. UFPR., $8: 15 \mathrm{p}$

VIANA, C.F.; GAMA, E.G., Jr.; SIMÕES, LA.; MOURA, J.A.; FONSECA, J.R.; ALVES, RJ. 1971. Revisão estratigráfica da Bacia Recôncavo/ Tucano. Boi Téc. Petrobrás, 14:157-192.

VILAS BOAS, G.S. \& BITTENCOURT, A.C.S.P. 1979. Mineralogia e composição química da fração argilosa dos sedimentos do fundo da Baía de Todos os Santos, Bahia. Rev. Bras.Geoc., 9:179-197.

VILAS BOAS. G.S. \& NASCIMENTO, M.A.M. 1979. Evolução paleogeográfica e paleoclimática da região das enseadas dos Tainheiros e dos Cabritos, BA, nos últimos 5.000 anos. Rev. Bras. Geoc., 9:159-168.

VISHER, G.S. 1969. Grain size distribution and depositional processes. J. Sed. Petrol, 39:1074-1106.

WOOD, L.E. 1964. Bottom sediments of Saginaw bay, Michigan. J. Sed. Petrol, 34:173-184.
MANUSCRITO A717

Recebido em 26 de fevereiro de 1992

Revisão do autor em 23 de abril de 1992

Revisão aceita em 5 de maio de 1992 